\title{
ESTIMULAÇÃO SENSÓRIO-MOTORA DE PESSOAS IDOSAS EM ISOLAMENTO SOCIAL DURANTE A PANDEMIA DE COVID-19
}

Meine Siomara Alcântara'

ORCID: 0000-0003-4977-3189

Rosemary Araújo Monteiro"

ORCID: 0000-0003-3666-0740

Maria Clara Silva de Melo"

ORCID: 0000-0002-8980-8043

Carlos Jordão de Assis Silva" ORCID: 0000-0002-9575-9030

Rejane Maria Paiva de Menezes" ORCID: 0000-0002-0600-0621

Luciane Paula Batista Araújo de Oliveira" ORCID: 0000-0003-1629-8991

'Secretaria Municipal de Saúde. Natal, Rio Grande do Norte, Brasil.

"Universidade Federal do Rio Grande do Norte. Natal, Rio Grande do Norte, Brasil.

Autor Correspondente: Luciane Paula Batista Araujo de Oliveira E-mail: lucianepoliveira@yahoo.com.br

Como citar: Alcântara MS, Monteiro RA, Melo MCS, Silva CJA, Menezes RMP, Oliveira LPBA. Estimulação sensóriomotora de pessoas idosas em isolamento social durante a pandemia de covid-19. In: Santana RF

(Org.). Enfermagem gerontologica no cuidado do idoso em tempos da COVID 19. 2.ed.rev. Brasilia, DF: Editora ABen; 2020. p 42-46. (Serie Enfermagem e Pandemias, 2). https://doi.org/10.51234/aben.20.e02.c07

\section{INTRODUÇÃO}

Em tempos de pandemia da COVID-19, o distanciamento social necessário à prevenção da transmissão da doença, impõe regras sociais que resultam numa situação de isolamento e solidão para as pessoas. Em se tratando de uma pessoa idosa destaca-se, especialmente àquele que vive sozinho, entendendo-se que momentos como esse, reforçam a importância de uma rede de apoio, com vistas a suprir suas necessidades, principalmente de segurança e proteção(1).

Pessoas de diferentes idades estão vivenciando problemas psicológicos durante esta pandemia, incluindo ansiedade, depressão e estresse ${ }^{(2)}$, o que torna mais preocupante quando se pensa em pessoas idosas vivendo na comunidade.

Vários são os aspectos levantados pelos profissionais de saúde relacionados aos idosos que são mais isolados, entre estes, ressalta-se a manutenção de sua capacidade funcional, envolvendo a realização das atividades básicas - como tomar banho, alimentar-se, vestir-se, deambular, controlar esfíncteres e usar o banheiro - e instrumentais de vida diária - como realizar compras, usar o telefone e outras ações mais complexas que envolvem interação social, cognição e memória ${ }^{(3)}$.

Quando a capacidade funcional se mantém preservada no envelhecimento, muitos são os benefícios para o estado de saúde do idoso, visto que os estímulos intelectuais, recreativos e sociais convergem para a manutenção das funções cognitivas ${ }^{(4)}$.

A pandemia da COVID-19 pode ter impacto negativo no comportamento das pessoas com relação às atividades físicas. Ao permanecerem isoladas e com distanciamento social por um longo período de tempo, podem ser afetadas por prováveis riscos de cargas físicas, psíquicas e emocionais.

O sedentarismo forçado pelo isolamento domiciliar pode causar impacto no estilo de vida e muito mais acentuado 
nas populações de risco nas quais incluem as pessoas idosas, com obesidade, diabetes, hipertensão, doença cardiovascular, histórico de tabagismo e doença pulmonar obstrutiva crônica (DPOC).

A realização de exercícios físicos visa principalmente a manutenção da capacidade aeróbica e da mobilidade articular. Além disso, melhora a atividade do sistema imunológico e diminuem o risco de queda e de desenvolvimento de sarcopenia, síndrome da fragilidade, osteopenia e distúrbios cognitivos. Para o idoso, o distanciamento social pode contribuir para o desenvolvimento de estresse e sintomas depressivos, e a prática de exercício físico pode atuar como uma terapia eficaz para saúde mental, como também, física e no controle das doenças crônicas ${ }^{(5)}$.

Entende-se que os profissionais de saúde, ao atenderem idosos em domicílio, se encontram em posição estratégica para promover atividades que estimulem a cognição desses usuários, considerando que o distanciamento social pode implicar em prejuízos a sua capacidade cognitiva e saúde mental. Nesse sentido, o presente relato de experiência foi construído com o propósito de compartilhar uma iniciativa dessa natureza, cujos resultados positivos junto a pessoas idosas poderão contribuir para que outros profissionais que vivem realidades semelhantes possam também replicá-la em seus serviços.

\section{OBJETIVO}

Relatar a experiência de ações envolvendo estimulação sensório-motora de pessoas idosas em isolamento social durante a pandemia de COVID-19.

\section{MÉTODOS}

Trata-se de um relato de experiência, com abordagem descritiva, que visa descrever ações do projeto Cuca Legal, uma iniciativa de uma enfermeira de uma unidade da Estratégia Saúde da Família (ESF) da cidade de Natal/RN, junto a professores e estudantes do Programa de Educação pelo Trabalho (PET) Interprofissional, contando com a parceria de enfermeiros do Departamento Científico de Enfermagem Gerontológica (DCEG), da Associação Brasileira de Enfermagem seção Rio Grande do Norte (ABEn RN).

O projeto teve suas atividades iniciadas no início do mês de maio de 2020 e o cenário de sua realização envolve a área adscrita à ESF Ponta Negra, localizada no distrito sanitário sul da cidade de Natal/RN. Trata-se de um bairro heterogêneo do ponto de vista socioeconômico, porém a referida unidade de saúde se localiza em uma região denominada de Vila de Ponta Negra, onde vivem pessoas de condição financeira mais precária, com elevado número de idosos. O público-alvo desse projeto são idosos residentes na comunidade que vivem sozinhos e em distanciamento social.

\section{RESULTADOS}

O projeto Cuca Legal foi proposto pensando nas pessoas idosas que costumavam frequentar os grupos de convivência e que, devido à pandemia, estão experimentando as implicações de viver em distanciamento social há mais de dois meses.

Como os idosos vivem cada vez mais sozinhos em muitos países, o distanciamento social associado ao COVID-19 pode afetar negativamente os aspectos físicos, de saúde mental e bem-estar dos idosos, particularmente aqueles com declínio cognitivo ou demência e que são altamente dependentes de cuidados $^{(6)}$.

O projeto consiste em promover atividades de estimulação sensório-motora e cognitiva que incluem exercícios de raciocínio lógico, cálculo, leitura, escrita e pintura, sendo essa última uma proposta para garantir a inclusão dos idosos com menor escolaridade e que não teriam como realizar as demais.

A equipe envolvida elaborou, até o momento, 170 kits contendo pasta, lápis grafite, borracha, apontador, lápis de cor e uma cartilha com as atividades supracitadas, foram entregues pelos Agentes Comunitários de 
Saúde (ACS) no domicílio dos idosos. Os materiais dos kits foram adquiridos através de doações da própria equipe bem como de comerciantes da cidade que continuam com as doações, para que mais idosos possam se beneficiar dessa ação.

Foi essa a forma que, respeitando as regras de distanciamento social, os profissionais encontraram de promover atividades que estimulam as habilidades e fornecem também entretenimento para os idosos, favorecendo a manutenção do vínculos e prevenindo declínio funcional.

Um estudo prospectivo e de coorte realizado na Suécia evidenciou a existência de associação entre aspectos das relações sociais e a incidência de demência em idosos. Observou-se que quanto maior o nível de relacionamento social menor o risco de estresse, sintomas depressivos e demências ${ }^{(7)}$.

Atualmente já se conhece a relação entre comprometimento cognitivo e incapacidade funcional na pessoa idosa, visto que o surgimento de declínio cognitivo implica no desempenho das atividades instrumentais de vida diária e quando a cognição tem comprometimento mais severo, o idoso passa a ter dificuldade até mesmo para as atividades básicas de vida diária, consideradas mais simples. Nessa perspectiva, é evidente a necessidade da detecção precoce de declínio cognitivo para que o profissional possa atuar na prevenção do declínio da capacidade funcional por meio da estimulação sensório-motora ${ }^{(8)}$, principalmente neste tempo de isolamento social.

É importante destacar que na cartilha constam não só atividades que estimulam a cognição como também constam algumas dicas de exercícios físicos, sendo esses expressos através de ilustrações que ensinam sobre os movimentos que o idoso poderá fazer dentro de sua própria casa, pensando nos benefícios para seu corpo e mente.

Além das ilustrações presentes na cartilha, também se encontra ao lado de cada exercício a descrição de como ele deve ser executado pelo idoso, bem como, sua finalidade terapêutica. Na primeira cartilha enviada nos kits estavam presentes exercícios para auxiliar no retorno venoso; exercícios de marcha estacionária (como se o idoso caminhasse sem sair do lugar), sentar e levantar para estimular a mobilidade, bem como para fortalecer os adutores de coxa e demais músculos dos membros inferiores; e flexão de ombro para mobilidade global de membros superiores. Todos esses exercícios estavam representados utilizando uma linguagem de fácil compreensão e com a orientação de como realizá-lo com segurança, além de mensagens motivacionais para o idoso.

Para orientar e recomendar com mais eficácia um programa de exercícios físicos apropriados, existem modelos e métodos destinados a manter e ou melhorar a reabilitação física durante a pandemia de COVID-19. Recomenda-se a participação regular em exercícios aeróbicos de intensidade moderada, além de atividades de fortalecimento muscular, equilíbrio, coordenação e alongamentos ${ }^{(5)}$.

A proposta é de continuar levando, semanalmente, novas cartilhas com mais exercícios e aproveitar o momento da entrega para saber como esses idosos estão se sentido. Também tem sido feito contato telefônico para saber se esses idosos estão apresentando algum sinal e/ou sintoma da COVID-19, como forma de evitar que os mesmos saiam de casa para ir até o serviço de saúde, evitando exposições desnecessárias. Assim, apenas àqueles considerados como casos suspeitos são orientados a buscar atendimento presencial.

A pandemia de COVID-19 trouxe desafios sem precedentes à humanidade e representa uma ameaça ainda maior para os idosos, por isso é crucial minimizar os riscos e atender às necessidades de saúde dessa população. Ao mesmo tempo, é necessário refletir que quando chegarmos no momento pós-pandemia teremos a oportunidade de preparar o terreno para uma sociedade equitativa e que lute pela garantia dos direitos humanos da pessoa idosa( ${ }^{(6)}$.

\section{Limitações do Estudo}

Até pouco tempo, a maior pandemia já registrada na história tinha sido a da Gripe Espanhola, ocorrida a mais de $100 \operatorname{anos}^{(9)}$. Sendo assim, essa é a primeira vez que a atual geração de enfermeiros enfrenta uma pandemia, fazendo com que cada experiência vivida seja acompanhada de muitas incertezas. O número de casos suspeitos, confirmados e óbitos permanecem crescendo em muitos países, bem como é também crescente a velocidade de divulgação de novas informações a cada dia. Apesar do grande número de publicações de documentos oficiais e artigos nacionais e internacionais, pouco se encontra sobre as repercussões da pandemia no contexto 
da Atenção Básica/Atenção Primária à Saúde, o que limita a discussão e/ou a comparação com experiências semelhantes a essa que tenham sido realizadas em outras localidades.

\section{Contribuições para a Área}

A principal contribuição da experiência ora relatada é a de mostrar que com poucos recursos e com articulação comunitária - para captar os donativos necessários - é possível desenvolver ações que estimulem o envelhecimento ativo.

Por ser uma ação realizada na ESF, essa experiência corrobora com as diretrizes da Política Nacional de Atenção Básica, mostrando como os profissionais de saúde que atuam nesse nível de atenção podem desenvolver ações que auxiliem as pessoas idosas a desenvolverem as condições necessárias para gerir e tomar decisões sobre sua própria saúde de forma mais efetiva, considerando as necessidades e potencialidades de cada um na busca de uma vida independente e plena ${ }^{(10)}$.

Enfermeiros e demais profissionais que atuam, estudam e pesquisam na área de gerontologia podem replicar a experiência do Projeto Cuca Legal em seus locais de trabalho, seja na comunidade ou em Instituições de Longa Permanência (ILPI), podendo acrescentar outras atividades que avaliem como pertinentes para esse público. Por meio de ações como essa, os profissionais podem contribuir para a promoção da saúde da pessoa idosa em suas múltiplas dimensões.

\section{CONSIDERAÇÕES FINAIS}

A equipe tem recebido manifestações positivas dos idosos e familiares, pois as atividades estimulam a cognição e promovem bem estar, amenizando o distanciamento e isolamento imposto pela pandemia.

A relação entre os riscos atuais de complicações de saúde, as taxas de mortalidade associadas ao COVID-19, isolamento social e o sedentarismo não pode ser ignorada, e possivelmente será tema para estudos posteriores. Por fazerem parte do grupo de risco da COVID-19, os idosos necessitam do distanciamento social, como também precisam manter uma rotina saudável que inclui a prática de atividades física e estimulação sensório-motora.

A permanência em casa requer o apoio da família, mas também o cuidado qualificado das equipes de Saúde da Família. O momento que vivemos é crítico, mas também oportuno para que seja reforçado nosso compromisso com a saúde da população idosa vivendo no território e com a promoção do cuidado centrado na pessoa. Assim, esperamos que a divulgação da experiência do projeto Cuca Legal seja capaz de estimular novas iniciativas que promovam o envelhecimento ativo e saudável mesmo durante a pandemia de COVID-19.

\section{AGRADECIMENTO}

Ao Departamento Científico de Enfermagem Gerontológica da ABEn Nacional.

À Equipe da unidade da Estratégia de Saúde da Família Ponta Negra e a todos os colaboradores do Projeto Cuca Legal.

\section{REFERÊNCIAS}

1. Argenta C, Nunes DP, Hammerschmidt KSA, Niwa LMS, Souza PA, Melo POC. Distanciamento social do idoso saudável durante a pandemia covid-19: possibilidades e desafios. In: Enfermagem gerontológica no cuidado ao idoso em tempos da COVID-19. Associação Brasileira de Enfermagem. Brasília: ABEn/DCEG, 2020. 74 p. (Série enfermagem e pandemias). [Internet]. 2020 [cited 2020 May 28]. Available from: http://www.abennacional.org.br/site/wp-content/uploads/2020/05/EBOOK-GERONTO.pdf 
2. Lima CKT, Carvalho PMM, Lima IAAS, Nunes JVAO, Saraiva JS, Souza RI, Silva CGL, Rolim Neto ML. The emotional impact of Coronavirus 2019-nCoV (new Coronavirus disease). Psychiatry Research 287 (2020) 1129152. doi: 10.1016/j. psychres.2020.112915

3. Dias EG, Andrade FB, Duarte YAO, Santos JLF, Lebrão ML. Atividades avançadas de vida diária e incidência de declínio cognitivo em idosos: Estudo SABE. Cad. Saúde Pública. 2015; 31(8): 1623-1635.doi:10.1590/0102-311X00125014

4. Imaginário C, Machado P, Rocha M, Antunes C, Martins T. Activities of daily living as cognitive state predictors for the institutionalized elderly. Rev Portuguesa Enferm Saúde Mental [Internet]. 2017 [cited 2020 May 31]; (18): 37-43. Available from: http://www.scielo.mec.pt/scielo.php?script=sci_arttext\&pid=S1647-21602017000300006\&lng=pt.

5. Jiménez-Pavón D, Carbonell-Baeza A, Lavie CJ. Physical exercise as therapy to fight against the mental and physical consequences of COVID-19 quarantine: Special focus in older people. Prog Cardiovasc Dis. 2020:1-3. doi:10.1016/j. pcad.2020.03.009

6. United Nations. Policy brief: the impact of Covid-19 on older persons. [Internet] 2020 [citede 2020 May 29]. Available from: https://unsdg.un.org/resources/policy-brief-impact-covid-19-older-persons

7. Sörman DE, Rönnlund M, Sundström A, Adolfsson R, Nilsson LG. Social relationships and risk of dementia: a populationbased study. International Psychogeriatrics. 2015; 27(8): 1391-1399. doi: 10.1017/S1041610215000319

8. Fagundes TA, Pereira DAG, Bueno KMP, Guimarães Assis MG. Incapacidade funcional de idosos com demência. Cad. Ter. Ocup. UFSCar, São Carlos [Internet]. 2017 [cited 2020 May 31]; 25(1): 159-169. Available from: http://www. cadernosdeterapiaocupacional.ufscar.br/index.php/cadernos/article/view/1540/827

9. Matos HJ. A próxima pandemia: estamos preparados? Rev Pan-Amaz Saude [Internet] 2018 jul-set; 9(3): 9-11. DOI: http:// dx.doi.org/10.5123/S2176-62232018000300001

10. Ministério da Saúde (BR). Portaria n².436, de 21 de setembro de 2017. Aprova a Política Nacional de Atenção Básica, estabelecendo a revisão de diretrizes para a organização da Atenção Básica, no âmbito do Sistema Único de Saúde (SUS). Brasília: Ministério da Saúde [Internet]. 2017 [cited 2020 May 30]. Available from: https://bvsms.saude.gov.br/bvs/ saudelegis/gm/2017/prt2436_22_09_2017.html 